Article

\title{
Water-Soluble Organic Germanium Promotes Both Cornified Cell Envelope Formation and Ceramide Synthesis in Cultured Keratinocytes
}

\author{
Megumi Kato ${ }^{1}$, Haifeng Zeng ${ }^{1}$, Lihao $\mathrm{Gu}^{1}$ and Kazuhisa Maeda ${ }^{1,2, *}$ \\ 1 Bionics Program, Tokyo University of Technology Graduate School, 1404-1 Katakuramachi, Hachioji City, \\ Tokyo 192-0982, Japan; canvivicam@yahoo.co.jp (M.K.); SteveZeng@hotmail.com (H.Z.); \\ chaos19901008@gmail.com (L.G.) \\ 2 School of Bioscience and Biotechnology, Tokyo University of Technology, 1404-1 Katakuramachi, \\ Hachioji City, Tokyo 192-0982, Japan \\ * Correspondence: kmaeda@stf.teu.ac.jp; Tel.: +81-42-6372442
}

Received: 29 July 2017; Accepted: 6 September 2017; Published: 9 September 2017

\begin{abstract}
We investigated whether 3-(trihydroxygermyl) propionic acid increases the formation of cornified cell envelopes and the level of ceramide in cultured epidermal keratinocytes and in a three-dimensional human epidermis model. The activity and mRNA expression of transglutaminase were increased when 3-(trihydroxygermyl) propionic acid was added to the cell cultures. The formation of cornified cell envelopes in cultured human epidermal keratinocytes was increased in the presence of 3-(trihydroxygermyl) propionic acid. Ceramide levels were increased in the presence of 3-(trihydroxygermyl) propionic acid. The activity of serine palmitoyltransferase and mRNA levels of serine palmitoyltransferase 2 were also increased when 3-(trihydroxygermyl) propionic acid was added to the cultures. The extent to which ceramide levels were increased in the presence of 3-(trihydroxygermyl) propionic acid appeared dependent on serine palmitoyltransferase 2 upregulation. These results suggest that 3-(trihydroxygermyl) propionic acid can promote cornified cell envelope formation by inducing transglutaminase expression and ceramide synthesis via the induction of serine palmitoyltransferase activity, thereby improving the barrier function and moisture of dry, rough skin.
\end{abstract}

Keywords: barrier function; ceramide; keratinization; organic germanium; transglutaminase

\section{Introduction}

The skin consists of subcutaneous tissue, dermis, and epidermis. The epidermis consists of basal, spinous, granular, and stratum corneum. The stratum corneum is formed through keratinization as keratinocytes in the epidermal basal layer divide. The primary roles of this layer are to provide moisture and function as a barrier [1]. The former function facilitates the retention of moisture and prevents drying, whereas the latter prevents the invasion of irritants from the environment and transpiration of water from the skin [1]. These functions are exerted by intercorneocyte lipids in the stratum corneum, which consist of ceramides (37\%), cholesterol (32\%), fatty acids (16\%), and cholesterol esters (15\%) [2]. The stratum corneum consists of thick cell membranes, inside of which a lining structure of the intracellular insoluble membrane, called a cornified cell envelope (CE), exists to strengthen the cell membrane [3,4].

Transglutaminase-1 (TGase1) is closely involved with the abovementioned processes [5,6], and catalyzes cross-linking between proteins during keratinization $[7,8]$. It is a transferase that condenses a primary amine of lysine to the amino group of glutamine and transfers a substituent on the amine to glutamine $[7,8]$. Omega-hydroxy ceramides attach outside CEs, and are required for 
keratinization $[9,10]$. Thus, both CEs and ceramides play important roles in maintaining normal barrier functions of the stratum corneum [3,4,11,12]. Ceramides are synthesized by the actions of enzymes, including serine palmitoyltransferase (SPTLC), which catalyzes the condensation of L-serine and palmitoyl-CoA during the keratinization of epidermal cells [11]. Following condensation, sphinganine is converted into sphingomyelin and glucosylceramide through various reactions, which are followed by reconversion into ceramides by $\beta$-glucocerebrosidase ( $\beta$ GCase) and acid sphingomyelinase (aSMase) [13].

Water-soluble organic germanium is added to cosmetics and bath salts to provide skin care benefits such as improving rough skin [14]. Trace amounts of germanium are contained in Pycnoporus cinnabarina, Allium sativum, Ginseng radix, Symphytum officinale, Theae folium, Coicis semen, and Sophora subprostrata [15]. Meanwhile, the detailed mechanism of the beneficial effects of the compound remains unclear. In the present study, we investigated the pharmaceutical effects of water-soluble organic germanium on epidermal keratinocytes to elucidate the mechanism underlying its benefits.

\section{Materials and Methods}

\subsection{Materials}

In the present study, 3-(trihydroxygermyl) propionic acid [ $\left.\left.\mathrm{Ge}(\mathrm{OH})_{3} \mathrm{CH}_{2} \mathrm{CH}_{2} \mathrm{COOH}\right)\right]$, which was used as a water-soluble form of bis(2-carboxyethylgermanium(IV) sesquioxide) [16], was obtained from Japan Algae Co., Ltd. (Tokyo, Japan). The three-dimensional human epidermis model (LabCyte EPI-MODEL24) and its culture medium were obtained from Japan Tissue Engineering Co., Ltd. (Aichi, Japan). Dulbecco's Modified Eagle Medium and fetal bovine serum were purchased from GIBCO (Life Technologies Japan, Tokyo, Japan) and BioWest (Funakoshi, Tokyo, Japan), respectively. 3-(Trihydroxygermyl) propionic acid (GeOH) was dissolved in phosphate-buffered saline (PBS) (Takara Bio Inc., Shiga, Japan) to prepare the culture medium. Other reagents used in experiments were obtained from Wako Pure Chemical Industries (Osaka, Japan).

\subsection{Effects of GeOH on the Protein Levels of TGase1, Involucrin, and SPTLC2 in Cultured Epidermal Keratinocytes}

HaCaT cells were cultured for 4 days in medium supplemented with 10 or $100 \mu \mathrm{g} / \mathrm{mL} \mathrm{GeOH}$ under a confluent condition to determine the protein levels of TGase1, SPTLC2, and involucrin by Western blotting (WB). The medium was removed from the dishes, followed by three washes with PBS. Subsequently, $500 \mu \mathrm{L}$ of Tris- $\mathrm{HCl}$ buffer (containing 1\% sodium dodecyl sulfate (SDS) and 1\% sodium deoxycholate (DOC), $\mathrm{pH}$ 7.4) was added for extraction. The viscosity of the extract was reduced using a syringe. The extracted proteins were measured at an absorbance of $562 \mathrm{~nm}$ using a BCA Protein Assay Kit-Reducing Agent Compatible (Pierce, Thermo Fisher Scientific Inc., Rockford, IL, USA). Following this, samples with the same protein concentrations were added to the samples containing the same amounts of protein, followed by a reaction for $5 \mathrm{~min}$ at $95^{\circ} \mathrm{C}$. A marker and the samples $(10 \mu \mathrm{g} / \mathrm{mL})$ were loaded into the wells and electrophoresed. Subsequently, the proteins in the gel were transferred to membranes. The membranes were immersed overnight in a blocking solution at $4{ }^{\circ} \mathrm{C}$. They were then immersed for $1 \mathrm{~h}$ in a solution containing anti-TGase1 (Harber Bio-Product, Norwood, MA, USA), anti-involucrin (\#SY5, Sigma-Aldrich), or anti-SPTLC2 (GeneTex Inc., Irvine, CA, USA), which were diluted 500-fold with Tris-buffered saline (TBS), as primary antibodies. The membranes were then washed with TBS-T and immersed for $1 \mathrm{~h}$ in a solution containing peroxidase-labeled anti-mouse antibody or anti-rabbit antibody, diluted 10,000-fold (for TGase1 and involucrin) or 2000-fold (for SPTLC2) with TBS, as a secondary antibody. Next, the membranes were washed and immersed for $10 \mathrm{~min}$ in a mixture of Western Blotting Detection Reagent (GE Healthcare Japan, Tokyo, Japan). They were subsequently transferred to a film for development. The detection bands were quantified using ImageJ (NIH, Bethesda, MD, USA). 


\subsection{Effects of GeOH on the mRNA Expression Levels of TGase1 and Involucrin in Cultured Epidermal Keratinocytes}

$\mathrm{HaCaT}$ cells were cultured for 3 days in medium supplemented with 10 or $100 \mu \mathrm{g} / \mathrm{mL} \mathrm{GeOH}$ under a confluent condition to determine the mRNA levels of TGase1 and involucrin using real-time polymerase chain reaction (real-time PCR). The total RNA was isolated from cells after 3 days of culture using an mRNA Extraction Kit (QIAGEN K.K., Tokyo, Japan) according to the manufacturer's instructions. Quantitative reverse transcription (RT)-PCR was performed using a Real-Time RT-PCR Kit (Takara Bio Inc., Shiga, Japan) and an ABI PRISM 7900HT system (Applied Biosystems, Forster City, CA, USA) according to the manufacturers' instructions. The glyceraldehyde-3-phosphate dehydrogenase (G3PDH) gene was amplified and used as an endogenous reference. The PCR reaction was performed as follows: $42{ }^{\circ} \mathrm{C}$ for $5 \mathrm{~min}$ and $95{ }^{\circ} \mathrm{C}$ for $10 \mathrm{~s}$, followed by 40 cycles of $95{ }^{\circ} \mathrm{C}$ for $5 \mathrm{~s}$ and $60{ }^{\circ} \mathrm{C}$ for $31 \mathrm{~s}$. The primers of TGase1, involucrin, and G3PDH were purchased from Invitrogen (Thermo Fisher Scientific K.K., Yokohama, Japan). The sequences of PCR primers used in this study were as follows: TGase1: forward primer, $5^{\prime}$-GCTCGAAGGCTCTGGGTT ACA-3'; reverse primer, 5'-TGCCACAGGCACAAACGAC-3'. Involucrin: forward primer, 5'-TAAC CACCCGCAGTGTAAAG-3'; reverse primer, 5'-CACCTAGCGGACCCGAAATAAG-3'. GAPDH: forward primer, 5' -GCACCGTCAAGGCTGAGAAC-3'; reverse primer, 5'-ACTGGCGCTTTCA CCACCACCAT- $3^{\prime}$. Using the $\Delta \Delta C$ t method, relative changes in mRNA expression were calculated and normalized to that of G3PDH.

\subsection{Measurement of TGase Activity Using a Biotin-Bound Substrate}

The activity of TGase was determined using a biotin-bound substrate [17]. TGase catalyzes cross-linking between proteins. In the present study, biotin-labeled pentylamine, i.e., a biotin-labeled primary amine, was incorporated by TGase into glutamine residues of protein involved in the reaction. Following this, TGase activity was determined by Western blotting using horseradish peroxidase (HRP)-conjugated streptavidin and chemiluminescence reagent. The effects of $\mathrm{GeOH}$ on the levels and activity of TGase were assayed in cultured epidermal keratinocytes. HaCaT cells were cultured for 3 days in medium supplemented with 10 or $100 \mu \mathrm{g} / \mathrm{mL} \mathrm{GeOH}, 1 \mathrm{~h}$ after adding $2 \mathrm{mmol} / \mathrm{L}$ biotin-labeled pentylamine. Then, the dish was washed with PBS, and $50 \mu \mathrm{L}$ each of Tris- $\mathrm{HCl}$ buffer (containing 1\% SDS and 1\% DOC, pH 7.4) was added to dissolved the cells. The extracted proteins were measured at an absorbance of $562 \mathrm{~nm}$ using a BCA Protein Assay Kit-Reducing Agent Compatible. Then, $2 \times$ SDS sample buffer was added, followed by vortexing. Following this, the microtubes were heated for $5 \mathrm{~min}$ in a thermostatic chamber at $95{ }^{\circ} \mathrm{C}$. The samples were loaded into a gel and electrophoresed. Subsequently, the gel underwent transfer blotting. The membrane was incubated with streptavidin-HRP diluted 1000-fold with TBS-T. The membrane was then washed in TBS-T. Finally, the membranes were washed and immersed for $10 \mathrm{~min}$ in a mixture of ECL Prime Western Blotting Detection Reagent.

\subsection{Effects of $\mathrm{GeOH}$ on $\mathrm{CE}$ Formation in Cultured Epidermal Keratinocytes}

$\mathrm{HaCaT}$ cells were cultured for 4 days in medium supplemented with $100 \mu \mathrm{g} / \mathrm{mL} \mathrm{GeOH}$ or $0.5 \mu \mathrm{g} / \mathrm{mL} 1 \alpha, 25$-dihydroxycholecalciferol under a confluent condition. The cells were counted before and after the addition of a protein solubilizer to calculate the ratio of CEs to total cells. The method to prepare keratinocytes with CEs has been described previously [18]. After trypsin treatment, keratinocytes were collected by centrifugation, and the cell count was determined using a hemocytometer. The remaining cells were treated with $10 \mathrm{mmol} / \mathrm{L}$ Tris- $\mathrm{HCl}(\mathrm{pH} 7.5)$ containing $2 \%$ SDS and $20 \mathrm{mmol} / \mathrm{L}$ dithiothreitol at $95{ }^{\circ} \mathrm{C}$ for $5 \mathrm{~min}$. This treatment ensures the persistence of only cells with CEs, which were then counted using a hemocytometer. 


\subsection{Three-Dimensional Culture of Human Epidermis}

The epidermis model is characterized by a stratified culture of human normal skin cells. It is morphologically like the human epidermis (i.e., it consists of basal, spinous, granular, and stratum corneum). For pretreatment, $500 \mu \mathrm{L}$ of accompanying assay medium were added to the well and allowed to stand for $1 \mathrm{~h}$ at $37^{\circ} \mathrm{C}$ in a $\mathrm{CO}_{2}$ incubator. Then, the assay medium was replaced with fresh medium. The epidermis models were cultured for 3 days in medium supplemented with $100 \mu \mathrm{g} / \mathrm{mL} \mathrm{GeOH}$ to determine the mRNA expression level of TGase1 using real-time PCR and immunohistochemical staining of TGase1 using the subsequently described method.

\subsection{Immunohistochemical Staining}

The epidermis model was cultured in the culture medium. One hour later, the culture medium was added to wells with or without (control) $100 \mu \mathrm{g} / \mathrm{mL}$ GeOH. After 3 days of culture, an optimum cutting temperature (O.C.T.) compound (Sakura Finetek Japan Co., Ltd., Tokyo, Japan) was added to prepare frozen sections. The frozen sections were immersed in methanol and allowed to stand for $5 \mathrm{~min}$ at $0{ }^{\circ} \mathrm{C}$. The sections were sufficiently dried and washed three times with PBS containing $0.01 \%$ bovine serum albumin (BSA). Next, goat serum diluted to $10 \%$ using PBS was dropped onto the sections. The glass slides were placed in a moisture chamber and allowed to stand for $1 \mathrm{~h}$ at room temperature. The slides were washed three times with PBS containing $0.01 \%$ BSA. Following this, anti-TGase1 monoclonal antibody (Harbor Bio-Products) diluted 500-fold with PBS containing 0.01\% BSA, was dropped onto the slides. The slides were allowed to stand overnight in a moisture chamber at $4{ }^{\circ} \mathrm{C}$. They were then washed three times with PBS containing $0.05 \%$ Tween 20 . Subsequently, Alexa Fluor 488 goat anti-mouse IgG (Invitrogen, Life Technologies, Rockville, MD, USA), diluted 1000-fold with PBS containing 0.01\% BSA, was dropped onto the slides. The slides were allowed to stand overnight in a moisture chamber at $4{ }^{\circ} \mathrm{C}$. They were subsequently washed five times with PBS containing 0.05\% Tween 20 and once with PBS. Fluoromount (Japan Tanner Corp., Osaka, Japan) was dropped onto the slides, and coverslips were mounted on them. Finally, the slides were examined using a fluorescence microscope (BX51, Olympus Corporation, Tokyo, Japan).

\subsection{Measurement of the Amount of Ceramide in the Epidermis Model Using Silica Gel Thin-Layer Chromatography}

After 3 days of incubation, the epidermis models were detached from the inserts. Lipid extraction solvent (chloroform:methanol = 2:1) was added, followed by vortexing and sonication. Subsequently, the cultures were centrifuged to extract lipids (lower phase). The remaining epidermis models were completely dried, followed by protein extraction with $200 \mu \mathrm{L}$ of extraction solution $(0.5 \mathrm{~mol} / \mathrm{L}$ Tris- $\mathrm{HCl}$ ( $\mathrm{pH} \mathrm{7.4)} \mathrm{containing} \mathrm{1 \%} \mathrm{DOC} \mathrm{and} \mathrm{1 \%} \mathrm{SDS).} \mathrm{The} \mathrm{extracted} \mathrm{proteins} \mathrm{were} \mathrm{measured} \mathrm{at} \mathrm{an}$ absorbance of $562 \mathrm{~nm}$ using a BCA Protein Assay Kit-Reducing Agent Compatible. Following this, the lipid extractions with the same protein concentrations were spotted onto a silica gel thin-layer plate, and $5 \mathrm{mg} / \mathrm{mL}$ ceramide 2 (N-stearoyl-dihydrosphingosine; TIC-001, Takasago International Corp., Tokyo, Japan) was used as a standard. The plate was sufficiently dried and developed twice in a solvent (chloroform:methanol:acetic acid = 190:9:1), followed by coloring with a sulfuric ceric ammonium molybdate (CAM) solution. The sulfuric CAM solution was prepared by dissolving $20 \mathrm{~mL}$ of concentrated sulfuric acid, $5 \mathrm{~g}$ of $\left(\mathrm{NH}_{4}\right)_{6} \mathrm{Mo}_{7} \mathrm{O}_{24} / 4 \mathrm{H}_{2} \mathrm{O}$, and $8 \mathrm{~g}$ of $\mathrm{Ce}\left(\mathrm{NH}_{4}\right)_{4}\left(\mathrm{SO}_{4}\right)_{4} / 2 \mathrm{H}_{2} \mathrm{O}$ in $180 \mathrm{~mL}$ of distilled water. The developed bands were quantified using ImageJ (NIH, Bethesda, MD, USA).

\subsection{Effects of $\mathrm{GeOH}$ on the Levels of Ceramides in the Epidermis Models}

The epidermis models were cultured for $1 \mathrm{~h}$ in medium supplemented with 10 or $100 \mu \mathrm{g} / \mathrm{mL}$ $\mathrm{GeOH}$ and cultured for 3 days. Following lipid extraction and the preparation of specified amounts of protein, ceramide levels were determined by thin-layer chromatography. 


\subsection{Effects of GeOH on the mRNA Expression Levels of Ceramide Synthesis Genes in the Epidermis Models}

The epidermis models were cultured for $1 \mathrm{~h}$ in medium supplemented with 10 or $100 \mu \mathrm{g} / \mathrm{mL}$ $\mathrm{GeOH}$ and cultured for 3 days. The mRNA expression levels of the SPTLC2, $\beta$ GCase, and aSMase genes were determined using real-time PCR. The primers of SPTLC $2, \beta G C a s e$, and aSMase were purchased from Invitrogen. The sequences of PCR primers used in this study were as follows: SPTLC2: forward primer, 5'-AGCCGCCAAAGTCCTTGAG-3'; reverse primer, 5'-CTTGTC CAGGTTTCCAATTTCC-3'. 3 GCase: forward primer, 5'-TGGCATTGCTGTACATTGG-3'; reverse primer, 5'-CGTTCTTCTGACTGGCAACC-3'. aSMase: forward primer, 5' -GCTGGCTCTATGAA GCGATGGC-3'; reverse primer, 5'-AGAGCCAGAAGTTCTCACGGGA-3'.

\subsection{Measurement of SPTLC Activity in Cultured Epidermal Keratinocytes by High-Performance Liquid Chromatography (HPLC)}

SPTLC activity was measured according to a previously described method [19]. SPTLC catalyzes the first, rate-limiting step in the de novo synthesis of sphingolipids, namely, the condensation of palmitoyl-CoA and L-serine to 3-ketodihydrosphingosine (3KDS). 3KDS is chemically reduced by $\mathrm{NaBH}_{4}$ to threo- and erythro-sphinganine, the ortho-phthalaldehyde (OPA) derivatives of which are separated by HPLC and quantified by fluorescence detection. The peak area of D-erythrodihydrosphinganine to the peak area of an internal standard (C17-sphingosine) was calculated, and the concentration of the sample was calculated from the analytical curve. Specifically, the cells were washed twice with PBS. They were then suspended in $1 \mathrm{~mL}$ of lysis buffer (PBS containing $1 \%$ sodium deoxycholate, $1 \%$ Triton $\mathrm{X}-100$, and $0.1 \mathrm{mmol} / \mathrm{L}$ ethylenediaminetetraacetic acid). The suspension was transferred into a new 1.5-mL tube, followed by sonication and centrifugation. Using the supernatant, the protein content of the suspension was determined. In total, $10 \mu \mathrm{L}$ of $20 \times$ HPLC assay mix $(125 \mu \mathrm{g}$ of $20 \mathrm{mmol} / \mathrm{L}$ L-serine, $20 \mu \mathrm{L}$ of $5 \mathrm{mmol} / \mathrm{L}$ pyridoxal $5^{\prime}$-phosphate hydrate, $50 \mu \mathrm{L}$ of $5 \mathrm{mmol} / \mathrm{L}$ palmitoyl-CoA lithium, and $55 \mu \mathrm{L}$ of pure water) was added to $190 \mu \mathrm{L}$ of the sample and immediately vortexed, followed by incubation for $1 \mathrm{~h}$ at $37^{\circ} \mathrm{C}$. Then, $50 \mu \mathrm{L}$ of sodium tetrahydroborate $(5 \mathrm{mg} / \mathrm{mL})$ was added and allowed to stand for $5 \mathrm{~min}$ at room temperature. From this solution, $125 \mu \mathrm{L}$ was transferred to a new 1.5-mL tube. Then, $1.6 \mu \mathrm{L}$ of $1 \mathrm{mmol} / \mathrm{L}$ C17-sphingosine (in ethanol) was added to $2 \mathrm{~mL}$ of methanolic $\mathrm{KOH}: \mathrm{CHCl}_{3}$ (4:1). From this solution, $250 \mu \mathrm{L}$ was transferred to the sample and vortexed. In total, $250 \mu \mathrm{L}$ of chloroform, $250 \mu \mathrm{L}$ of alkaline water, and $2 \mathrm{~mol} / \mathrm{L} \mathrm{NH}_{4} \mathrm{OH}$ were added to the solution, followed by vortexing and centrifugation to remove the supernatant. The lower phase was washed twice with $450 \mu \mathrm{L}$ of alkaline water $\left(2 \mathrm{mmol} / \mathrm{L} \mathrm{NH}_{4} \mathrm{OH}\right)$. Next, $250 \mu \mathrm{L}$ of the lower phase was transferred to a new 1.5-mL tube followed by chloroform evaporation. The residue was dissolved in $75 \mu \mathrm{L}$ of solution (methanol:ethanol:pure water $=85: 47.5: 17.5$ ). Following this, $75 \mu \mathrm{L}$ of HPLC standard mix (0.6 $\mathrm{mol} / \mathrm{L} \mathrm{C17-sphingosine}+0.6 \mu \mathrm{mol} / \mathrm{L}$ D-erythro-dihydrosphinganine) was added to a new 1.5-mL tube. To this, $2.5 \mu \mathrm{L}$ of $0.5 \mathrm{mg} / \mathrm{mL}$ OPA boric acid solution was added and allowed to stand for $2 \mathrm{~h}$ in the dark. HPLC was conducted using a C18 reverse phase column (Capcell Pak, Shiseido Co., Ltd., Tokyo, Japan) under the following conditions: $5 \mathrm{mmol} / \mathrm{L}$ phosphate buffer ( $5 \mathrm{mmol} / \mathrm{L} \mathrm{Na}_{2} \mathrm{HPO}_{4}: 5 \mathrm{mmol} / \mathrm{L} \mathrm{NaH}_{2} \mathrm{PO}_{4}$ [61:39]); injection volume, $5 \mu \mathrm{L}$; flow rate, $1 \mathrm{~mL} / \mathrm{min}$; pump program, 0-20 min, methanol:5 mmol/L phosphate buffer ( $\mathrm{pH} 7.0)$ (90:10), 20-25 min, methanol (100\%), and 25-30 min, methanol:5 mmol/L phosphate buffer (pH 7.0) (85:15); and fluorescence detection wavelength, Ex./Em. = 335/440 nm.

\subsection{Data Analysis}

Statistical differences regarding the ratio of the numbers of cells and CEs, SPTLC2 levels, and the activities of $\beta$ GCase and aSMase were determined using a two-tailed Student's $t$-test. For RT-PCR, statistical analysis was performed at the $\Delta C t$ stage to exclude potential bias due to the averaging of data transformed through the equation $2^{-\Delta \Delta C t}$, and statistical significance was determined using a two-tailed Student's t-test, as reported previously [20]. All results were expressed as the mean \pm standard deviation (S.D.). 


\section{Results}

\subsection{Effects of $\mathrm{GeOH}$ on the Expression of Keratinization-Related Proteins in Cultured Epidermal Keratinocytes}

The morphology of epidermal keratinocytes in the presence of 10 and $100 \mu \mathrm{g} / \mathrm{mL} \mathrm{GeOH}$ was observed under the microscope. The mechanism underlying the beneficial effect of $\mathrm{GeOH}$ on keratinization-related proteins such as TGase1 and involucrin was examined. The expression levels of keratinization-related proteins, such as TGase 1 and involucrin, were examined by WB. We found that the levels of TGase1 and involucrin were increased in the presence of 10 and $100 \mu \mathrm{g} / \mathrm{mL} \mathrm{GeOH} \mathrm{(Figure} \mathrm{1).}$

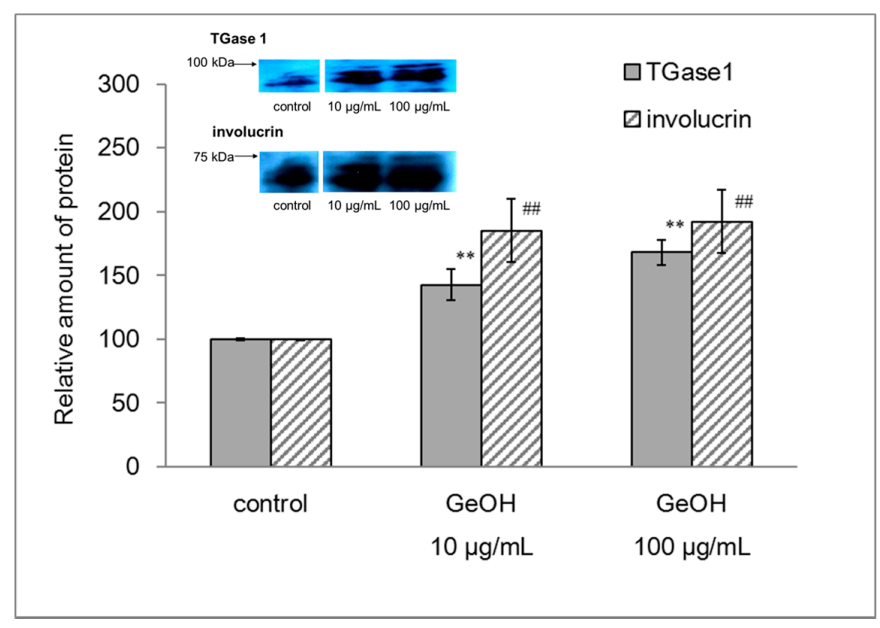

Figure 1. Effects of $\mathrm{GeOH}$ on TGase1 and involucrin expression in cultured epidermal keratinocytes. $\mathrm{HaCaT}$ cells were cultured for 4 days in medium supplemented with 10 or $100 \mu \mathrm{g} / \mathrm{mL} \mathrm{GeOH}$, and the protein levels of TGase1 and involucrin were determined by Western blotting when the same amount of proteins was loaded. The results are presented as the mean \pm S.D. of three experiments. ${ }^{* *} p<0.01$ vs. TGase1 control, ${ }^{\# \#} p<0.01$ vs. involucrin control.

\subsection{Effects of GeOH on the mRNA Expression Levels of TGase1 and Involucrin in Cultured Epidermal Keratinocytes}

We also examined the mRNA expression levels of TGase1 and involucrin following the addition of $\mathrm{GeOH}(10$ and $100 \mu \mathrm{g} / \mathrm{mL})$ to the culture medium using real-time PCR. We found a significant increase in the mRNA levels of TGase1 after treatment with 10 and $100 \mu \mathrm{g} / \mathrm{mL} \mathrm{GeOH}$ in cultured epidermal keratinocytes (Figure 2). We found a significant increase in the mRNA levels of involucrin after treatment with $100 \mu \mathrm{g} / \mathrm{mL} \mathrm{GeOH}$ in cultured epidermal keratinocytes (Figure 2).
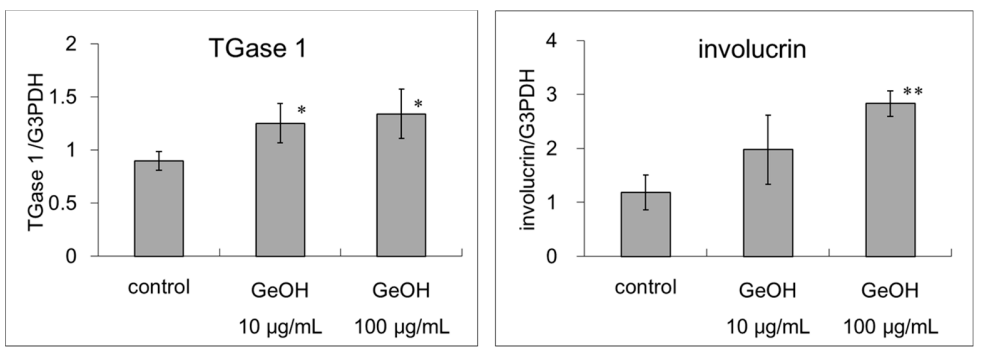

Figure 2. Effects of $\mathrm{GeOH}$ on TGase1 and involucrin mRNA expression levels in cultured epidermal keratinocytes. HaCaT cells were cultured for 3 days in medium supplemented with 10 or $100 \mu \mathrm{g} / \mathrm{mL}$ $\mathrm{GeOH}$. Total RNA was isolated from the cells, and quantitative reverse transcription-polymerase chain reaction was performed using three samples. The results are shown relative to the control. ${ }^{*} p<0.05$ vs. control, ${ }^{* *} p<0.01$ vs. control. 


\subsection{Effects of GeOH on TGase Activity in Cultured Epidermal Keratinocytes}

TGase activity following the addition of $\mathrm{GeOH}$ was determined using a biotin-bound pentylamine. The measurement of TGase activity is shown in Figure 3. Because TGase condenses biotin-labeled pentylamine and the amino residue of glutamine in proteins in the cell, almost all bands are stained densely if TGase activity is high. Bands of the samples supplemented with $\mathrm{GeOH}$ at both 10 and $100 \mu \mathrm{g} / \mathrm{mL}$ are more intense than those of the control, indicating increased TGase activity following treatment with $\mathrm{GeOH}$.

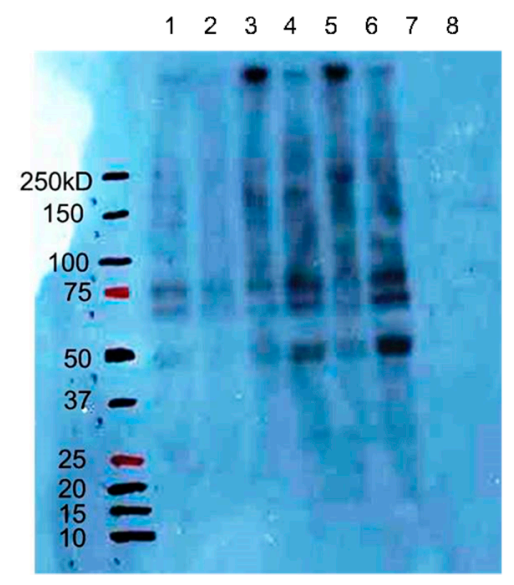

Figure 3. Effects of $\mathrm{GeOH}$ on TGase activity in cultured epidermal keratinocytes. HaCaT cells were cultured for 3 days in medium supplemented with or without (control) 10 or $100 \mu \mathrm{g} / \mathrm{mL} \mathrm{GeOH}$, and the activity of TGase was determined by Western blotting with biotin-bound pentylamine when the same amount of proteins was loaded. Lanes 1 and 2 are controls, lanes 3 and 5 are $10 \mu \mathrm{g} / \mathrm{mL} \mathrm{GeOH}$, lanes 4 and 6 are $100 \mu \mathrm{g} / \mathrm{mL} \mathrm{GeOH}$, and lanes 7 and 8 are biotin (-). Biotin (-) represents the samples incubated without biotin-bound pentylamine.

\subsection{Effects of GeOH on the Expression of TGase1 in a Three-Dimensional Human Epidermis Model}

The mRNA expression level of TGase1 in the three-dimensional human epidermis model is shown in Figure 4a. Compared with the control, the expression level of TGase1 was significantly increased following the addition of $100 \mu \mathrm{g} / \mathrm{mL} \mathrm{GeOH}$. Immunohistochemically, TGase1 was more strongly stained in the presence of $100 \mu \mathrm{g} / \mathrm{mL} \mathrm{GeOH}$. Thus, increased TGase1 expression may be involved in the keratinization-promoting effects of $\mathrm{GeOH}$ (Figure $4 \mathrm{~b}$ ).

\subsection{Effects of $\mathrm{GeOH}$ on $\mathrm{CE}$ Formation in Cultured Epidermal Keratinocytes}

The effects of $\mathrm{GeOH}$ on $\mathrm{CE}$ formation associated with the barrier functions of the stratum corneum were examined because TGase1 is closely involved in the formation of robust CEs. The results are shown in Figure 5. Compared with the control, the ratio of CEs to cells was increased significantly by the addition of $100 \mu \mathrm{g} / \mathrm{mL} \mathrm{GeOH}$. CE formation was more strongly promoted by $100 \mu \mathrm{g} / \mathrm{mL}$ than by $0.4 \mu \mathrm{g} / \mathrm{mL}$ activated vitamin D3 (1 $\alpha, 25$-dihydroxycholecalciferol), which has been reported to promote $\mathrm{CE}$ formation [21]. The effects of $\mathrm{GeOH}$ were compared with those of activated vitamin D3, demonstrating that $\mathrm{GeOH}$ was more effective than activated vitamin D3. 
a

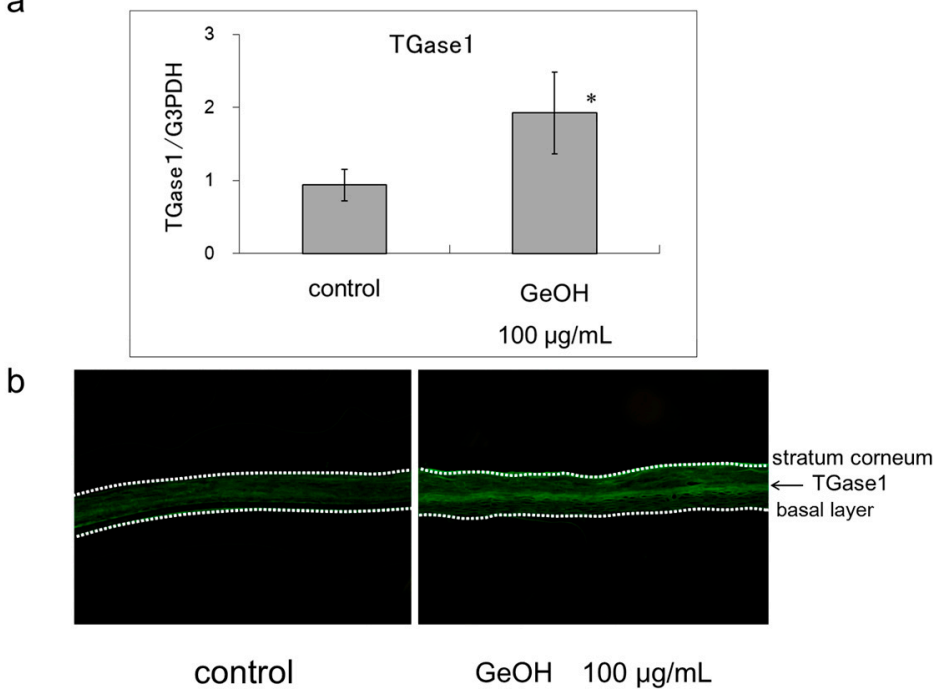

Figure 4. Effect of $\mathrm{GeOH}$ on TGase1 expression level in a three-dimensional human epidermis model. (a) mRNA expression level: Epidermis models were cultured for 3 days in medium supplemented with $100 \mu \mathrm{g} / \mathrm{mL} \mathrm{GeOH}$. Total RNA was isolated from the cells, and quantitative reverse transcription-polymerase chain reaction was performed using four samples. The results are shown relative to the control. ${ }^{*} p<0.05$ vs. control at the $\Delta \mathrm{Ct}$ stage; (b) Immunohistochemical staining: After 3 days of culture of the epidermis models with or without $\mathrm{GeOH}$, cryosections were stained with anti-TGase1 monoclonal antibody and Alexa Fluor 488 goat anti-mouse IgG. The results are presented as the representative result of three experiments.

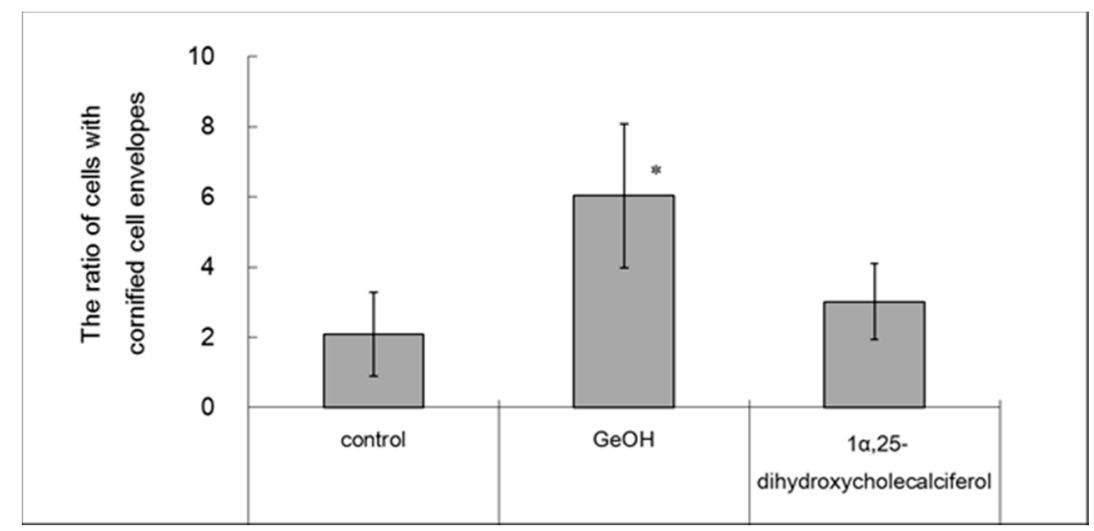

Figure 5. Effect of $\mathrm{GeOH}$ on cornified cell envelope (CE) formation in cultured epidermal keratinocytes. $\mathrm{HaCaT}$ cells were cultured for 4 days in medium supplemented with $100 \mu \mathrm{g} / \mathrm{mL} \mathrm{GeOH}$ or $0.5 \mu \mathrm{g} / \mathrm{mL}$ $1 \alpha, 25$-dihydroxycholecalciferol. CE formation was evaluated before and after the addition of a protein solubilizer to calculate the ratios of CEs to the total cell counts. The results are presented as the mean \pm S.D. of three experiments. ${ }^{*} p<0.05$ vs. control.

\subsection{Effects of $\mathrm{GeOH}$ on the Amount of Ceramide in the Epidermis Model}

In addition to $\mathrm{CE}$ formation, ceramide in the extracellular matrix of the stratum corneum promotes skin barrier and moisturizing functions. The effect of $\mathrm{GeOH}$ on the levels of ceramide in the epidermis model was examined by thin-layer chromatography. The results are shown in Figure 6. Ceramide content was increased by the addition of 10 and $100 \mu \mathrm{g} / \mathrm{mL} \mathrm{GeOH}$. 


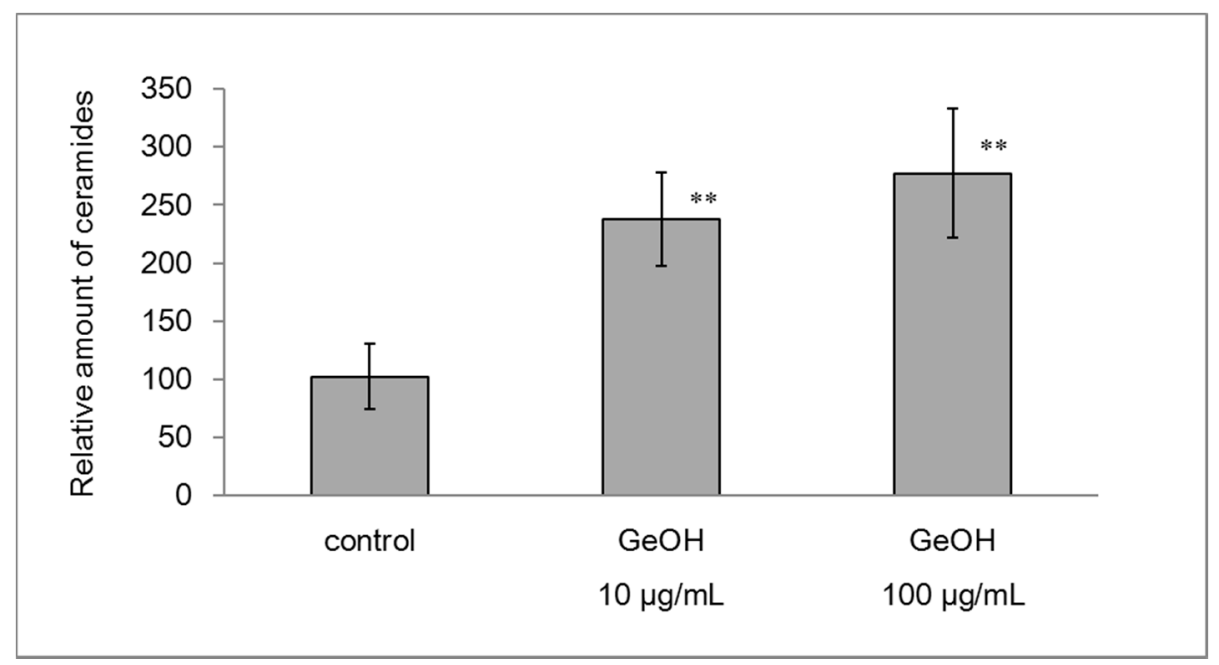

Figure 6. Effects of $\mathrm{GeOH}$ on ceramides levels in the epidermis model. The levels of ceramides ( 1 and 2 ) in the epidermis model cultured for 3 days with or without $\mathrm{GeOH}$ were measured by silica gel thin-layer chromatography. The results are presented as the mean \pm S.D. of three experiments. ** $p<0.01$ vs. control.

\subsection{Effect of $\mathrm{GeOH}$ on the mRNA Expression Levels of Ceramide Synthesis Genes in the Epidermis Model}

Next, we examined the effect of $\mathrm{GeOH}$ on the mRNA expression levels of a number of genes involved in ceramide synthesis, including SPTLC2, a rate-limiting enzyme of ceramide synthesis, and $\beta G C a s e$ and aSMase, which convert glucosylceramide and sphingomyelin, respectively, in the lamellar granules into ceramide. The results are shown in Figure 7. The mRNA expression level of SPTLC2 was significantly increased in the presence of $100 \mu \mathrm{g} / \mathrm{mL} \mathrm{GeOH}$. Meanwhile, the mRNA expression levels of $\beta$ GCase and aSMase were not altered by $\mathrm{GeOH}$.

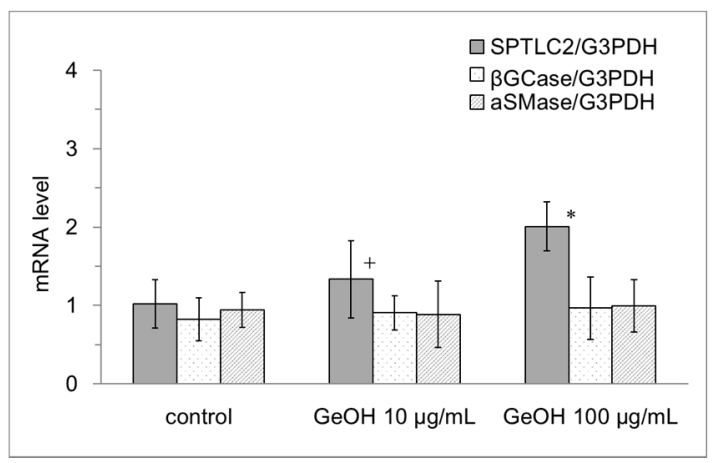

Figure 7. Effects of $\mathrm{GeOH}$ on ceramide synthesis gene mRNA expression in the epidermis model. Epidermis models were cultured for 3 days in medium supplemented with 10 or $100 \mu \mathrm{g} / \mathrm{mL} \mathrm{GeOH}$. Total RNA was isolated from the cells, and quantitative reverse transcription-polymerase chain reaction was performed using six samples. The results are shown relative to the control. ${ }^{*} p<0.05$ vs. control, $+p<0.1$ vs. control.

\subsection{Effects of $\mathrm{GeOH}$ on the Levels and Activity of SPTLC in Cultured Epidermal Keratinocytes}

Similar to the effects of $\mathrm{GeOH}$ on the mRNA expression levels of SPTLC2 in the epidermis model, the protein levels of SPTLC2 were increased significantly by the addition of 10 and $100 \mu \mathrm{g} / \mathrm{mL} \mathrm{GeOH}$ in cultured epidermal keratinocytes (Figure 8a). SPTLC activity in cultured epidermal keratinocytes was 
also measured. Similar to the mRNA expression level of SPTLC2, the measured SPTLC activities were increased significantly by 10 and $100 \mu \mathrm{g} / \mathrm{mL} \mathrm{GeOH}$ in cultured epidermal keratinocytes (Figure 8b).

a

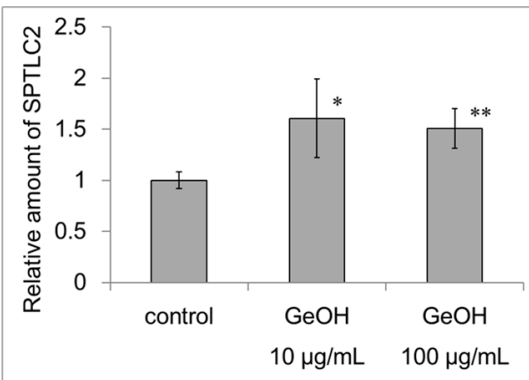

b

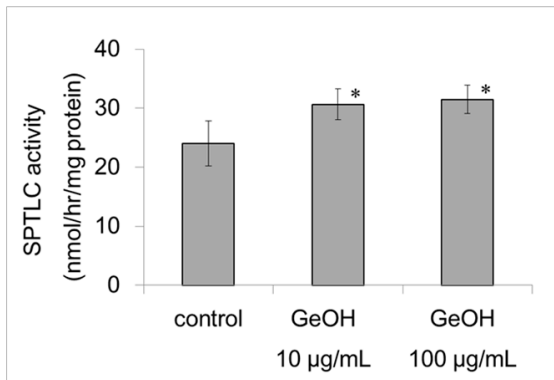

Figure 8. Effect of $\mathrm{GeOH}$ on serine palmitoyltransferase (SPTLC) levels and activity in cultured epidermal keratinocytes. HaCaT cells were cultured for 3 days in medium supplemented with 10 or $100 \mu \mathrm{g} / \mathrm{mL} \mathrm{GeOH}$. (a) Subsequently, Western blotting was performed using anti-SPTLC2 and anti-peroxidase-labeled rabbit secondary antibodies. The results are presented as the mean \pm S.D. of four experiments. ${ }^{*} p<0.05$ vs. control, ${ }^{* *} p<0.01$ vs. control. (b) SPTLC activity was measured using high-performance lipid chromatography (HPLC)-based assay. HaCaT cell extracts were prepared. Subsequently, 3-ketosphinganine, which was generated from L-serine and palmitoyl-CoA through the catalytic action of SPTLC, was reduced with $\mathrm{NaBH}_{4}$ to generate threo- and erythro-sphinganine. The products were allowed to react with ortho-phthalaldehyde to measure SPTLC activities by HPLC (Ex. $335 \mathrm{~nm}$ and Em. $440 \mathrm{~nm}$ ). The results are presented as the mean \pm S.D. of four experiments. * $p<0.05$ vs. control.

\section{Discussion}

Numerous factors are involved in the mechanism underlying epidermal keratinization. Of these, TGase1 catalyzes the formation of $\varepsilon$ - $(\gamma$-glutamyl) lysine cross-links, and is closely involved in the formation of robust CEs, which facilitate the barrier functions of the stratum corneum $[5,22]$. In rough skin with a compromised barrier function, $\varepsilon$-( $\gamma$-glutamyl) lysine cross-linking induced by TGase is insufficient, precluding the formation of robust CEs and reducing the levels of intercorneocyte ceramides $[9,10,23]$. TGase1 is an enzyme that strengthens the barrier function of the stratum corneum and participates in the formation of strong CEs [5]. Therefore, it is an important enzyme for normal stratum corneum formation. In the present study, effects of $\mathrm{GeOH}$ on $\mathrm{CE}$ formation were examined, demonstrating that $\mathrm{GeOH}$ more strongly promoted $\mathrm{CE}$ formation at the optimal concentration. Therefore, $\mathrm{GeOH}$ normalizes keratinization, strengthening the barrier functions of the stratum corneum. Cell death was not observed at 10 and $100 \mu \mathrm{g} / \mathrm{mL} \mathrm{GeOH}$; however, growth was suppressed at $100 \mu \mathrm{g} / \mathrm{mL} \mathrm{GeOH}$, possibly owing to its promotion of keratinization. TGase1 was examined regarding its mRNA expression, protein expression, and activity in cultured keratinocytes in addition to its immunological staining patterns in an epidermis model. GeOH promoted both the mRNA and protein expression of TGase1 and increased its activity in epidermal keratinocytes. In the epidermis model, $\mathrm{GeOH}$ promoted the gene expression of TGase1 and increased its staining intensity. Thus, increased TGase1 expression may be involved in the keratinization-promoting effects of GeOH. GeOH facilitates TGase1 expression at the mRNA level and CE formation, thereby normalizing keratinization and enhancing the barrier functions of the stratum corneum.

Ceramide is present in the stratum corneum, and it is involved in the moisturizing and barrier functions of the skin [3,4]. Histologically, another water-soluble organic germanium compound (Ge-Vit) has been demonstrated to decrease the symptoms of atopic dermatitis [24], indicating that it may be useful for treating this condition. Therefore, we examined whether immature keratinization can be improved by $\mathrm{GeOH}$. In this study, we found that the levels of ceramide are increased in the presence of $\mathrm{GeOH}$. The effects of $\mathrm{GeOH}$ on SPTLC2, an enzyme required for the first reaction in the ceramide 
synthesis pathway, as well as aSMase and $\beta$ GCase, were examined. We found that GeOH increases the mRNA levels of SPTLC2 and the levels of ceramide. Thus, the expression and activity of SPTLC in human keratinocytes were determined by WB and HPLC. The results were consistent with those of real-time PCR. GeOH did not significantly alter the mRNA expression or activity of $\beta$ GCase and aSMase. There was no difference in the activities of $\beta$ GCase or aSMase in the presence of GeOH in the epidermis model (data not shown). The mRNA expression and protein expression and the activities of both TGase1 and SPTLC2 were investigated after 3 or 4 days of culture. The levels and activities of these proteins were increased, and the results agreed with the increase in their mRNA expression. It is necessary to clarify the mechanism that participates in the increased expression of TGase1 and SPTLC2 in cultures in the future.

\section{Conclusions}

TGase1 is involved in the formation of robust CEs that line the cell membrane of keratinocytes and play an important role in normal stratum corneum formation. Ceramides are required for the formation of intercorneocyte lipids and are critical for barrier functions to prevent the invasion of irritants from the environment, as well as for moisturizing functions to retain moisture in vivo. GeOH promotes both CE formation and SPTLC2 in cultured keratinocytes, and would thus be effective for treating rough skin with compromised barrier functions.

Acknowledgments: The authors gratefully acknowledge the technical assistance of Miyoko Fukuda.

Author Contributions: M.K., H.Z., L.G. and K.M. performed the experiments. K.M. designed the study and performed the analysis. M.K., H.Z., L.G. and K.M. interpreted the data and drafted the manuscript. K.M. supervised the progress and critically revised the manuscript. All authors read and approved the final manuscript.

Conflicts of Interest: The authors declare no conflict of interest.

\section{References}

1. Elias, P.M. Stratum corneum defensive functions: An integrated view. J. Investig. Dermatol. 2005, 125, $183-200$. [CrossRef] [PubMed]

2. Norlén, L.; Nicander, I.; Rozell, B.L.; Ollmar, S.; Forslind, B. Inter- and intra-individual differences in human stratum corneum lipid content related to physical parameters of skin barrier function in vivo. J. Investig. Dermatol. 1999, 112, 72-77. [CrossRef] [PubMed]

3. Holleran, W.M.; Feingold, K.R.; Man, M.Q.; Gao, W.N.; Lee, J.M.; Elias, P.M. Regulation of epidermal sphingolipid synthesis by permeability barrier function. J. Lipid Res. 1991, 32, 1151-1158. [PubMed]

4. Rogers, J.; Harding, C.; Mayo, A.; Banks, J.; Rawlings, A. Stratum corneum lipids: The effect of ageing and the seasons. Arch. Dermatol. Res. 1996, 288, 765-770. [CrossRef] [PubMed]

5. Matsuki, M.; Yamashita, F.; Ishida-Yamamoto, A.; Yamada, K.; Kinoshita, C.; Fushiki, S.; Ueda, E.; Morishima, Y.; Tabata, K.; Yasuno, H.; et al. Defective stratum corneum and early neonatal death in mice lacking the gene for transglutaminase 1 (keratinocyte transglutaminase). Proc. Natl. Acad. Sci. USA 1998, 95, 1044-1049. [CrossRef] [PubMed]

6. Candi, E.; Schmidt, R.; Melino, G. The cornified envelope: A model of cell death in the skin. Nat. Rev. Mol. Cell Biol. 2005, 6, 328-340. [CrossRef] [PubMed]

7. Griffin, M.; Casadio, R.; Bergamini, C.M. Transglutaminases: Nature's biological glues. Biochem. J. 2002, 368, 377-396. [CrossRef] [PubMed]

8. Lorand, L.; Graham, R.M. Transglutaminases: Crosslinking enzymes with pleiotropic functions. Nat. Rev. Mol. Cell Biol. 2003, 4, 140-156. [CrossRef] [PubMed]

9. Nemes, Z.; Marekov, L.N.; Fésüs, L.; Steinert, P.M. A novel function for transglutaminase 1: Attachment of long-chain omega-hydroxyceramides to involucrin by ester bond formation. Proc. Natl. Acad. Sci. USA 1999, 96, 8402-8407. [CrossRef] [PubMed]

10. Behne, M.; Uchida, Y.; Seki, T.; de Montellano, P.O.; Elias, P.M.; Holleran, W.M. Omega-hydroxyceramides are required for corneocyte lipid envelope (CLE) formation and normal epidermal permeability barrier function. J. Investig. Dermatol. 2000, 114, 185-192. [CrossRef] [PubMed] 
11. Stachowitz, S.; Alessandrini, F.; Abeck, D.; Ring, J.; Behrendt, H. Permeability barrier disruption increases the level of serine palmitoyltransferase in human epidermis. J. Investig. Dermatol. 2002, 119, 1048-1052. [PubMed]

12. Doering, T.; Brade, H.; Sandhoff, K. Sphingolipid metabolism during epidermal barrier development in mice. J. Lipid Res. 2002, 43, 1727-1733. [CrossRef] [PubMed]

13. Hamanaka, S.; Hara, M.; Nishio, H.; Otsuka, F.; Suzuki, A.; Uchida, Y. Human epidermal glucosylceramides are major precursors of stratum corneum ceramides. J. Investig. Dermatol. 2002, 119, 416-423. [CrossRef] [PubMed]

14. Yamaguchi, H.; Shimada, Y.; Takeda, T.; Nakamura, T.; Mano, N. A novel extraction method based on a reversible chemical conversion for the LC/MS/MS analysis of the stable organic germanium compound Ge-132. Anal. Chem. 2015, 87, 2042-2047. [CrossRef] [PubMed]

15. Mino, Y.; Oto, N.; Sakao, S.; Shimomura, S. Determination of germanium in medicinal plants by atomic absorption spectrometry with electrothermal atomization. Chem. Pharm. Bull. 1980, 28, 2687-2691. [CrossRef] [PubMed]

16. Akiba, M.; Kakimoto, N. Synthesis and properties of poly[3,3'-(1,3-dioxo-1,3-digermoxanediyl) bispropanoic acid] (Ge-132) and related compounds as bioactive organogermanium compound. J. Chem. Soc. Jpn. Chem. Ind. Chem. 1994, 3, 286-300. (In Japanese)

17. Zhang, J.; Lesort, M.; Guttmann, R.P.; Johnson, G.V. Modulation of the in situ activity of tissue transglutaminase by calcium and GTP. J. Biol. Chem. 1998, 273, 2288-2295. [CrossRef] [PubMed]

18. Murakami, M.; Hyodo, S.; Fujikawa, Y.; Fujimoto, T.; Maeda, K. Photoprotective effects of inclusion complexes of fullerenes with polyvinylpyrrolidone. Photodermatol. Photoimmunol. Photomed. 2013, 29, 196-203. [CrossRef] [PubMed]

19. Rütti, M.F.; Richard, S.; Penno, A.; von Eckardstein, A.; Hornemann, T. An improved method to determine serine palmitoyltransferase activity. J. Lipid Res. 2009, 50, 1237-1244. [CrossRef] [PubMed]

20. Baker, A.R.; Silva, N.F.; Quinn, D.W.; Harte, A.L.; Pagano, D.; Bonser, R.S.; Kumar, S.; McTernan, P.G. Human epicardial adipose tissue expresses a pathogenic profile of adipocytokines in patients with cardiovascular disease. Cardiovasc. Diabetol. 2006, 5, 1. [CrossRef] [PubMed]

21. Kragballe, K.; Wildfang, I.L. Calcipotriol (MC 903), a novel vitamin $\mathrm{D}_{3}$ analogue stimulates terminal differentiation and inhibits proliferation of cultured human keratinocytes. Arch. Dermatol. Res. 1990, 282, 164-167. [CrossRef] [PubMed]

22. Steinert, P.M.; Marekov, L.N. The proteins elafin, filaggrin, keratin intermediate filaments, loricrin, and small proline-rich proteins 1 and 2 are isodipeptide cross-linked components of the human epidermal cornified cell envelope. J. Biol. Chem. 1995, 270, 17702-17711. [CrossRef] [PubMed]

23. Törmä, H.; Lindberg, M.; Berne, B. Skin barrier disruption by sodium lauryl sulfate-exposure alters the expressions of involucrin, transglutaminase 1, profilaggrin, and kallikreins during the repair phase in human skin in vivo. J. Investig. Dermatol. 2008, 128, 1212-1219. [CrossRef] [PubMed]

24. Lim, D.H.; Li, M.; Seo, J.A.; Lim, K.M.; Ham, S.W. A novel organogermanium protected atopic dermatitis induced by oxazolone. Bioorg. Med. Chem. Lett. 2010, 20, 4032-4034. [CrossRef] [PubMed]

(C) 2017 by the authors. Licensee MDPI, Basel, Switzerland. This article is an open access article distributed under the terms and conditions of the Creative Commons Attribution (CC BY) license (http://creativecommons.org/licenses/by/4.0/). 